\title{
PENGARUH PERCEIVED ORGANIZATIONAL SUPPORT TERHADAP TURNOVER INTENTION DENGAN JOB SATISFACTION SEBAGAI VARIABEL MEDIASI PADA PT. BANK MNC DI JAKARTA PUSAT
}

\author{
Felix Herianto dan Yanuar \\ Program Studi Manajemen Fakultas Ekonomi dan Bisnis, Universitas Tarumanagara, Jakarta \\ Email: felixherianto88@gmail.com: yanuar@fe.untar.ac.id
}

\begin{abstract}
: this study aims to determine the influence of perceived organizational support on turnover intention through job satisfaction as mediating variable both indirectly or directly. The sample in this study were 75 employees of PT. Bank MNC at Jakarta Pusat, whom the majority are sales divition, a minimum sample is determine by using Hair's formula which are the indicators times with five. The analysis method used is SmartPLS 3.2.8 resulting in Perceived Organizational Support has a positive and significant effect on job satisfaction. Job satisfaction has a negative and not significant effect on turnover intention. Perceived organizational support has a negative and not significant effect on turnover intention. And perceived organizational support has a negative and not significant effect on turnover intention through job satisfaction as a mediating variable. The implication of this research is that the company is expected to increase perceived organizational support for employees to increase job satisfaction, then the next research party is expected to re-examine perceived organizational support for turnover intention, job satisfaction with turnover intention and perceived organizational support for turnover intention through job satisfaction because of the results of this study not significant..
\end{abstract}

Keywords: perceived organizational support, job satisfaction, turnover intention.

\section{LATAR BELAKANG}

Perkembangan ekonomi perbankan di Indonesia saat ini berkembang cukup pesat. Peranan bank merupakan sebagai stabilitas moneter yang tepat agar kegiatan ekonomi bisa berjalan dengan baik. Dengan adanya stabilitas moneter tersebut maka perbankan dapat menetapkan suatu kebijakan moneter. Oleh karena itu, sektor perbankan memiliki peranan penting bagi pemerintah sebagai peningkatan pertumbuhan ekonomi nasional. Peranan tersebut menjadi fungsi utama sebagai lembaga intermediasi antara debitur dengan kreditur.

Bank menjadi sebuah jembatan bagi pembiayaan sektor riil dalam rangka peningkatan iklim usaha dan iklim investasi atau sebagai rangka penciptaan lapangan kerja bagi masyarakat. Oleh karena itu industri masing-masing perbankan harus memerlukan strategi perencanaan yang strategis agar dapat bersaing secara kompetitif. Industri pada masing-masing perbankan akan menjadi organisasi dalam mengatur, mengawasi dan mengontrol karyawannya untuk mencapai tujuan masing-masing perbankan.

Perusahaan pada perbankan merupakan suatu rangkaian organisasi yang harus dilakukan dengan bekerja sama agar tercapainya tujuan bersama. Dalam menunjang kegiatan usaha organisasi pada perbankan, agar memiliki karyawan atau tenaga kerja yang berkompeten maka diperlukannya persepsi dukungan organisasi yang dilakukan oleh perusahaan. Menurut Armstrong dan Stassen (dalam Zumrah,A.R., dan Boyle,S., 2015) mengatakan bahwa sikap atau perilaku kerja pada karyawan bisa dipengaruhi oleh persepsi karyawan itu sendiri mengenai faktor-faktor kunci yang akan menjadi salah satu ciri organisasi karyawan tersebut. 
Karyawan yang menjalankan tugasnya agar tujuan perusahaan atau organisasi tercapai memerlukan persepsi dukungan organisasi yang baik. Oleh karena itu pemimpin harus menunjukan seberapa jauh organisasi atau perusahaan peduli dengan kesejahteraan para karyawan dan menghargai kontribusi para karyawan. Dengan persepsi karyawan mengenai dukungan organisasi, maka hasil pekerjaan dan kemampuan dapat dilihat secara keseluruhan dengan pandangan bagaimana karyawan merasa dibebankan dalam penugasannya.

Adapun fenomena tingkat turnover karyawan di mana pada tahun 2014, sebuah survei yang dilakukan oleh Pricewaterhouse Coopers (PwC) Indonesia terhadap industri perbankan di Indonesia menunjukkan tingkat turnover karyawan di sektor ini mencapai $15 \%$ yang mana survei tersebut melibatkan 30 bank besar di Indonesia, di mana dari hasil survei tersebut, 4\% diantaranya menyatakan mereka melakukan pindah kerja (turnover intention) karena merasa kurangnya faktor job satisfaction dalam bekerja di perusahaan perbankan kemudian $4 \%$ lagi karena merasa kurangnya faktor perceived organizational support pada organisasi perbankan sehingga menyebabkan mereka melakukan turnover intention

tingkat turnover pada PT. Bank MNC Internasional Tbk tercatat sebesar 32,37\% di mana hal ini telah melebihi rata-rata tingkat turnover karyawan perbankan di Indonesia yang hanya mencapai 15\% (Annual report MNC Bank, 2018:134). Hal tersebut mendorong peneliti menjadikan karyawan PT Bank MNC Internasional Tbk menjadi objek penelitian pada penelitian ini yang mana merupakan salah satu bank besar di Jakarta, yang pada tahun 2019 memiliki 59 cabang di Jakarta.

\section{KAJIAN TEORI}

Teori perceived organizational support memiliki tiga aspek yang menjadi perhatian utama dari karyawan ( Tang et al., 2017 ): sikap dari organisasi terhadap ide-ide karyawan yaitu apabila organisasi mendengarkan ide-ide karyawan serta menggunakannya, maka persepsi dukungan organisasi karyawan akan menjadi positif. Namun, persepsi dukungan organisasi karyawan akan menjadi negatif bila perusahaan tidak mendengarkan masukan atau ide dari karyawan walaupun segala keputusan diambil oleh pimpinan dalam perusahaan.

Respon yang diberikan terhadap karyawan yang mengalami masalah yaitu Apabila organisasi tidak menunjukan tindakan atau usaha untuk membantu karyawan ketika dalam masalah akan membuat karyawan berfikir bahwa tidak adanya dukungan yang dilakukan oleh organisasi terhadap karyawan ketika dalam masalah.

Respon yang diberikan terhadap kesehatan dan kesejahteraan karyawan yaitu Karyawan akan menilai bahwa organisasi peduli atau tidak kepada karyawannya dalam menunjang kesejahteraan dan kesehatan karyawannya dalam mencapai tujuan bersama.

\section{Teori Job Satisfaction}

Kepuasan kerja merupakan suatu respon yang positif karyawan terhadap pekerjaan yang diberikan dari penilaiannya. Kepuasan kerja adalah sikap dengan komponen kognitif serta afektif menurut Fisher (dalam Huning,T.M., Hurt, K.J., dan Frieder, R,E., 2020)

Dalam kepuasan kerja terdapat beberapa dimensi dalam mengungkapkan karakteristik mengenai pekerjaan ( Soegandhi et al., 2013), yang dimensi nya sebagai berikut:

a. Pekerjaan itu sendiri (work it self), yaitu setiap pekerjaan membutuhkan suatu keterampilan yang sesuai dengan bidangnya masing-masing. Permasalahan didalam suatu pekerjaan dan perasaan individu bahwa keahliannya dibutuhkan dalam melakukan suatu pekerjaan, akan meningkatkan atau mengurangi kepuasan kerja. 
b. Gaji atau upah (pay) menjadi suatu faktor dalam pemenuhan kebutuhan hidup karyawan yang dianggap layak atau tidak.

c. Promosi ( promotion) menjadi salah satu faktor yang mempunyai hubungan kesempatan untuk memperoleh peningkatan jenjang karir selama bekerja diperusahaan.

d. Atasan (supervision), sebagai pimpinan yang baik harus menghargai pekerjaan karyawannya. Menurut karyawan , pimpinan atau atasan dianggap sebagai sosok yang harus bertanggung jawab atas karyawannya.

e. Teman dalam bekerja ( workers ) merupakan faktor penting dalam hubungan antara karyawan dengan pimpinan dan karyawan lainnya , apapun jenis pekerjaannya.

\section{Teori Turnover Intention}

Niat pada turnover karyawan diartikan sebagai sebuah keinginan yang direncanakan atau disengaja untuk meninggalkan suatu organisasi. Niat dari turnover itu sendiri dianggap sebagai perilaku karyawan yang spesifik terkait dengan penarikan didalam organisasi ( Madden,L., Mathias, BD dan Madden, TM., 2015 ).

Turnover Intention telah berkolerasi dengan nilai aktual, oleh karena itu adanya niat pergantian karyawan merupakan suatu pertanda buruk bagi setiap organisasi , karena akan melibatkan suatu biaya yang dirasakan dan tidak dirasakan ( Huang, WR dan Su, CH., 2016 ).

Gambar 1. Model Penelitian

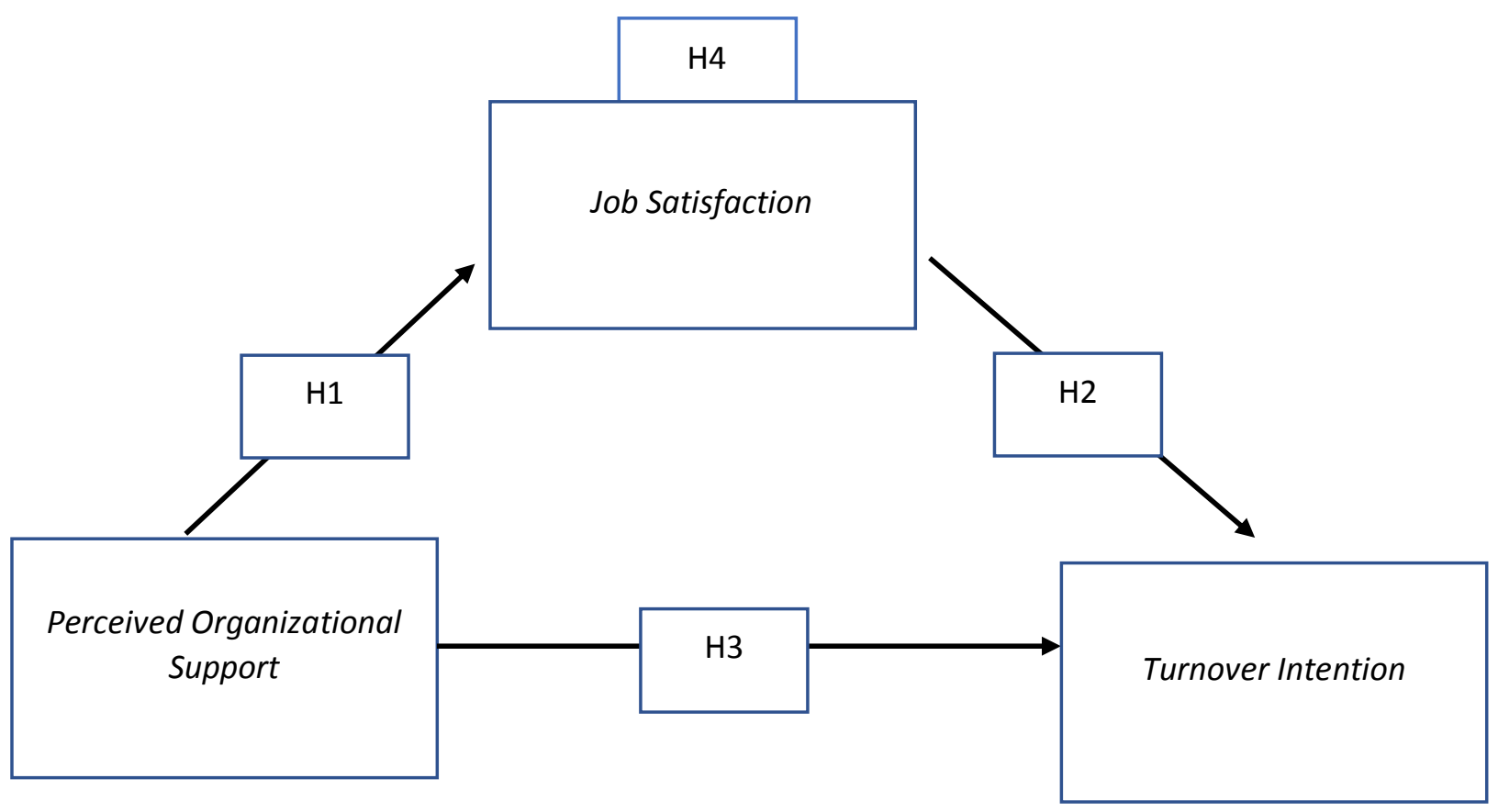

\section{Hipotesis}

H1 : Perceived Organizational Support mempunyai pengaruh signifikan terhadap Job Satisfaction.

H2 : Job Satisfaction mempunyai pengaruh signifikan terhadap Turnover Intention

H3 : Perceived Organizational Support mempunyai pengaruh signifikan terhadap Turnover Intention 
H4 : Perceived Organizational Support mempunyai pengaruh signifikan terhadap Turnover Intention dengan Job Satisfaction sebagai variabel mediasi

\section{METODOLOGI}

Pada penelitian ini menggunakan metode penelitian deskriptif yaitu menyebarkan sejumlah kuesioner yang dibagikan pada karyawan Bank MNC di Jakarta Pusat dan menggunakan pendekatan kuantitatif yang akan digunakan dalam penelitian ini. Populasi dari penelitian ini adalah karyawan PT. Bank MNC di Jakarta Pusat sebanyak 75 orang. Pada sampel yang dipakai untuk penelitian ini adalah karyawan yang berdomisili di Jakarta Pusat yang dimana mereka adalah karyawan Bank MNC. Dalam teknik pemilihan sampel yang digunakan dalam penelitian ini yaitu dengan purposive sampling. Sugiyono (2014:126) menjelaskan bahwa purposive sampling merupakan cara atau teknik dalam pengambilan sampel dengan menentukan sumber data dari ketentuan pada suatu data sehingga berjalan sesuai fungsinya. Menurut Hair et al. (2014) bahwa metode SEM atau Structural Equation Modeling membuat serangkaian hubungan dari analisis yang dilakukan untuk menghasilkan data dengan statistik.

Pengukuran variabel-variabel dalam penelitian ini mengacu pada penelitian sebelumnya antara lain sebagai berikut:

\begin{tabular}{lll} 
Variabel & Indikator & Acuan \\
\hline Perceived Organizational Support & 5 item & $\begin{array}{l}\text { Ahmed dan } \\
\text { Nawaz (2015) }\end{array}$ \\
\hline Job Satisfaction & 5 item & Hendri (2019) \\
\hline Turnover Intention & & $\begin{array}{l}\text { Lin, Tsai dan } \\
\text { Mahatma (2017) }\end{array}$
\end{tabular}

\section{HASIL ANALISIS DATA}

Analisis validitas, baik convergent validity maupun discriminant validity, telah dilakukan dengan menggunakan analisis average variance extracted, loading factors, dan cross loading. Hasilnya seluruh variabel dan indikator dalam penelitian ini valid untuk digunakan. Ketiga variabel yang digunakan dalam penelitian ini juga dinyatakan reliabel, karena memiliki nilai composite reliability diatas 0,70 dan nilai cronbach's alpha diatas 0,60 (Hair et al, 2014).

Berdasarkan hasil uji koefisien determinasi $\left(\mathrm{R}^{2}\right)$, pada variabel job satisfaction terdapat nilai sebesar 0.183 , dari nilai tersebut menjelaskan bahwa persentase job satisfaction dijelaskan dari perceived organizational support yaitu 18,3\%. Kemudian, pada variabel turnover intention terdapat nilai sebesar 0.046, dari nilai tersebut menjelaskan bahwa persentase tersebut dijelaskan dari perceived organizational support yaitu sebesar 4,6\%. Berdasarkan hasil pengujian di atas dapat disimpulkan bahwa nilai $R$-Square dalam penelitian ini tergolong moderate (Hair et al., 2017). Sedangkan hasil uji predictive relevance $\left(\mathrm{Q}^{2}\right)$, pada variabel job satisfaction dari hasil $\mathrm{Q}^{2}$ yaitu sebesar 0.106, hasil ini relevan karena telah sesuai dari rule of thumb $\mathrm{Q}^{2}>0$. Kemudian, pada variabel turnover intention dari hasil $\mathrm{Q}^{2}$ yaitu sebesar 0.005 , hasil ini relevan karena $\mathrm{Q}^{2}$ pada turnover intention > 0 ( Hair et al., 2014). 
Tabel 1. Hasil Pengujian Hipotesis

\begin{tabular}{lccc}
\multicolumn{1}{c}{ Variabel } & Original Sample & t-statistics & p-values \\
\hline $\begin{array}{l}\text { Perceived Organizational Support } \\
\rightarrow \text { Job Satisfaction }\end{array}$ & 0,428 & 3,449 & $\mathbf{0 . 0 0 1}$ \\
\hline $\begin{array}{l}\text { Perceived Organizational Support } \\
\rightarrow \text { Turnover Intention }\end{array}$ & $-0,184$ & 1,283 & $\mathbf{0 . 2 0 0}$ \\
\hline $\begin{array}{l}\text { Job satisfaction } \rightarrow \text { Turnover Intention } \\
\text { Perceived Organizational Support } \rightarrow\end{array}$ & $-0,056$ & 0,324 & $\mathbf{0 , 7 4 6}$ \\
$\begin{array}{l}\text { Job Satisfaction } \rightarrow \text { Turnover } \\
\text { Intention }\end{array}$ & $-0,024$ & 0,301 & $\mathbf{0 , 7 6 3}$
\end{tabular}

Hasil Pengujian H1 Berdasarkan hasil uji bootstrapping pada nilai path coefficient memiliki nilai sebesar 0.428 yang berati terdapat hubungan positif. Pada nilai $t$-statistics sebesar 3.449 yang telah melewati angka minimumnya yaitu sebesar 1.96 dan nilai p-value sebesar 0.001, nilai tersebut dibawah dari angka 0.05 , hal ini berati menunjukan bahwa hubungan antara perceived organizational support terhadap job satisfaction memiliki pengaruh positif dan signifikan, dan hipotesis ini diterima.

Hasil Pengujian H2 Berdasarkan hasil uji bootstrapping pada nilai path coefficient memiliki nilai sebesar -0.056 yang berhubungan negatif. Pada nilai $t$-statistics sebesar 0.324 dan nilai $p$-value 0.746, sehingga menunjukan hubungan antara job satisfaction terhadap turnover intention memiliki pengaruh negatif dan tidak signifikan, maka hipotesis $\mathrm{H} 2$ ini ditolak.

Hasil Pengujian H3 Berdasarkan hasil uji bootstrapping pada nilai path coefficient memiliki nilai sebesar -0.184 yang berati terdapat hubungan negatif. Pada nilai $t$-statistics sebesar 1.283, angka tersebut dibawah angka minimumnya yaitu sebesar 1.96 dan nilai $p$-value 0.200 , nilai tersebut berada diatas angka 0.05 , sehingga menunjukan bahwa hubungan antara Perceived Organizational Support terhadap Turnover Intention memiliki hubungan negatif dan tidak signifikan, maka hipotesis H3 ini ditolak.

Hasil Pengujian H4 Berdasakan hasil uji bootstrapping pada nilai path coefficient memiliki nilai sebesar -0.024 yang berati terdapat hubungan negatif. Pada nilai $t$-statistics sebesar 0.301 , angka tersebut dibawah angka minimumnya yaitu sebesar 1.96 dan nilai $p$-value 0.763 , nilai tersebut berada diatas angka 0.05 , sehingga menunjukkan bahwa hubungan antara perceived organizational support terhadap turnover intention dengan job satisfaction sebagai variabel mediasi memiliki hubungan negatif dan tidak signifikan, maka hipotesis $\mathrm{H} 4$ ini ditolak.

\section{DISKUSI}

Dengan diterimanya $\mathrm{H} 1$, apabila semakin tinggi persepsi dukungan organisasi yang dirasakan karyawan akan meningkatkan juga kepuasan kerja karyawan. Persepsi dukungan organisasi bagi karyawan merupakan peranan penting sehingga bisa berdampak pada sikap karyawan terhadap perusahaan. Dengan persepsi dukungan organisasi yang baik, karyawan akan merasa kehadiran mereka dihargai sehingga adanya tingkat kepuasan dalam bekerja.

Kemudian berdasarkan teori, Rhoades dan Eisenberger (Zumrah, AR. dan Boyle,S., 2015) menyatakan bahwa persepsi dukungan organisasi mengacu pada suatu persepsi karyawan tentang organisasi didalam perusahaannya melakukan penilaian atas kontribusi atau kinerja yang dilakukan karyawan pada tempat kerja dan kepedulian organisasi terhadap kesejahteraan karyawannya, kemudian 
Dengan diterimanya $\mathrm{H} 2$, Walaupun dengan variabel pada job satisfaction mampu menurunkan turnover intention namun job satisfaction tidak mempunyai pengaruh terhadap turnover intention. Hal ini sesuai dengan penelitian sebelumnya yang mengatakan adanya hubungan negatif antara dua variabel tersebut menurut Huang dan Su (2016) dan Huang et al (2017) namun pada penelitian ini menjelaskan bahwa hubungan kedua variabel tersebut tidak signifikan. Kemudian berdasarkan teori, Ramalho Luz dkk (2018) kepuasan kerja merupakan perasaan karyawan mengenai aspek-aspek yang telah ditentukan dan didapat didalam perusahaan

Dengan diterima H3, Hal ini menunjukan bahwa perceived organizational support tidak mempunyai pengaruh terhadap turnover intention. Hal ini terdapat kesamaan dengan penelitian terdahulu yang mengatakan bahwa variabel perceived organizational support tidak memiliki hubungan dengan turnover intention menurut Alhasmi, Jabeen, dan Papastathopoulus (2019). Tetapi hasil penelitian ini tidak sejalan dengan hasil penelitian Madden, L.,Mathias,BD dan Madden,TM. (2015) yang mengatakan bahwa persepsi dukungan organisasi berpengaruh negatif terhadap niat turnover.

Dengan diterima H4, Pada penelitian ini menjelaskan bahwa perceived organizational support memiliki pengaruh negatif dan tidak signifikan terhadap turnover intention dengan job satisfaction sebagai variabel mediasi. Pada perceived organizational support yang baik tidak memungkinkan bahwa niat karyawan untuk melakukan turnover intention itu tidak ada, walaupun secara tidak langsung didukung oleh variabel job satisfaction, karena pada penelitian ini menemukan bahwa hubungan kedua variabel tersebut dengan variabel mediasi tidak memiliki pengaruh terhadap karyawan. Hal ini sejalan dengan penelitian terdahulu yang juga tidak menemukan pengaruh antara ketiga variabel tersebut menurut Huning, Hurt, dan Frieder (2020).

\section{KESIMPULAN}

Berdasarkan hasil dari penelitian dan penjelasan yang telah dilakukan atas penelitian perceived organizational support terhadap turnover intention dengan job satisfaction sebagai variabel mediasi pada PT. Bank MNC di Jakarta Pusat bahwa Hipotesis satu (H1) adalah perceived organizational support mempunyai pengaruh terhadap job satisfaction, artinya peningkatan dari perceived organizational support menyebabkan karyawan mengalami job satisfaction dalam pekerjaan. Hipotesis dua (H2) adalah job satisfaction mempunyai pengaruh sehingga menurunkan tingkat intensitas karyawan untuk pindah ke perusahaan lain atau turnover intention. Hipotesis tiga (H3) adalah perceived organizational support mempunyai pengaruh terhadap turnover intention dengan adanya peningkatan perceived organizational support maka tingkat turnover intention mengalami penurunan. Hipotesis empat $(\mathrm{H} 4)$ adalah perceived organizational support terhadap turnover intention dengan job satisfaction sebagai variabel mediasi mempunyai pengaruh dan tidak signifikan, variabel perceived organizational support dan turnover intention mediasi oleh variabel job satisfaction.

Saran untuk perusahaan yaitu Perusahaan disarankan untuk meningkatkan perceived organizational support kepada karyawan agar dapat meningkatkan job satisfaction karyawan yang mana jika karyawan dengan job satisfaction yang tinggi kemungkinan akan dapat menurunkan tingkat turnover intention karyawan meskipun pada hasil statistik penelitian ini tidak signifikan tetapi penelitian terdahulu dan teori mendukung bahwa job satisfaction dapat menurunkan tingkat turnover karyawan.

Saran untuk peneliti selanjutnya Bagi peneliti selanjutnya disarankan untuk menambah variabel-variabel baru selain variabel perceived organizational support dan job satisfaction, 
karena variabel tersebut tidak signifikan dalam mempengaruhi turnover intention. Sehingga diperlukannya variabel baru yang mungkin dapat menekan angka turnover intention secara signifikan.

\section{DAFTAR PUSTAKA}

Huning, T.M., Hurt, K.J. \& Frieder, R.E. (2020). The Effect of Servant Leadership, Perceived Organizational Support, Job Satisfaction, and Job Embeddedness on Turnover Intentions: An Empirical Investigations. Evidence Based HRM. 8(2), 177-194.

Tang, G., Yu, B., Cooke, F.L. \& Chen, Y. (2017). High Performance Work System and Employee Creativity: The Role of Perceived Organizational Support and Development Management. Personnel Review. 46(7), 1318-1334.

Zumrah, A.R. \& Boyle, S. (2015). The Effect of Perceived Organizational Support and Job Satisfaction on Tranfer of Training. Personal Review. 44(2), 236-254.

Huang, W.R. \& Shu, C.H. (2016). The Mediating Role of Job Satisfaction in The Relationship between Job Training Satisfaction and Turnover Intentions. Industrial and Commercial Training. 48(1), 42-52.

Madden, L., Mathias, B.D. \& Madden, T.M. (2015). In Good Company: The impact of Perceived Organizational Support and Positive Relationships at Works on Turnover Intentions. Management Research Review. 38(3), 242-263

Soegandhi, V.M. (2013). Pengaruh Kepuasan Kerja dan Loyalitas Kerja terhadap Organizational Citizenship Behavior pada Karyawan PT. Surya Timur Sakti Jatim. Agora. 1(1).

AlHasmi, M., Jabeen, F., \& Papastathopoulos, A. (2019). Impact of Leader-Member Exchange and Perceived Organizational Support on Turnover Intention, Policing: An International Journal.

Hair, J.F.Jr., Hult, G.T.M., Ringle, C.M. \& Sarstedt, M. (2014). A Primer Partial Least Squares Structural Equation Modeling (PLS-SEM). Unit ed Stage: Sage.

Hair, J.F.Jr., Hult, G.T.M., Ringle, C.M. \& Sarstedt, M. (2017). A Primer Partial Least Squares Structural Equation Modeling (PLS-SEM). 2nd Edition. Thousand Oaks, CA: Sage.

Huang, S., Chen, Z., Liu, H. \& Zhou, L. (2017). Job Satisfaction and Turnover Intention in China: The Moderating Effects of Job Alternatives and Policy Support. Chinese Management Studies. 11(4), 689-706.

Sugiyono (2014) Metode penelitian kuantitatif kualitatif dan R\&D. Bandung: Alfabeta 